\title{
Rx for data-rich, access-poor researchers
}

$\mathrm{S}$ ocial insurance information, clinical data, population-based registries, income tax data, surveys unquestionably Canada is one data-rich nation. Unfortunately for researchers who are interested in national or comparative analyses, much of that data is locked up in provincial research centres. That may change within a year.

A new consortium, the Pan-Canadian Real-world Health Data Network, is being developed by a team of research and policy heavy hitters from the Canadian Institute for Health Information (CIHI), the Institute for Clinical Evaluative Sciences (ICES), the Canadian Network for Observational Drug Effect Studies (CNODES), the Manitoba Centre for Health Policy and Population Data BC.

"The multiprovince data platform is essential for innovation and transformation of the Canadian health care system," said Kimberlyn McGrail, a network founder and chair of the advisory board for Population Data BC.

Through the new network, which will include a health and social data council and a national coordinating centre, researchers and policy-makers will access real-word data via shared algorithms. The data could be used for benchmarking, evaluating novel interventions, research and innovation.

"We're trying to create some connectors that will make it possible for researchers to do cross-provincial research that doesn't require starting from ground zero every time," said McGrail at a recent panel discussion at the Canadian Association of Health Services and Policy Research in Montréal. "We will increase robustness of research so that we all mean the same thing by variable $\mathrm{x}$ in Manitoba, BC or Ontario."

The infrastructure will include harmonized common data that are already available, added Dr. Michael Schull, president and CEO of ICES. "Harmonization is the process of making these comparable, by running algorithms so we can do interprovincial analysis." Available data would include demographic, outpatient, medication, mortality and diagnostic. Over time, other data may be added; Manitoba, for example, has just introduced lab data.

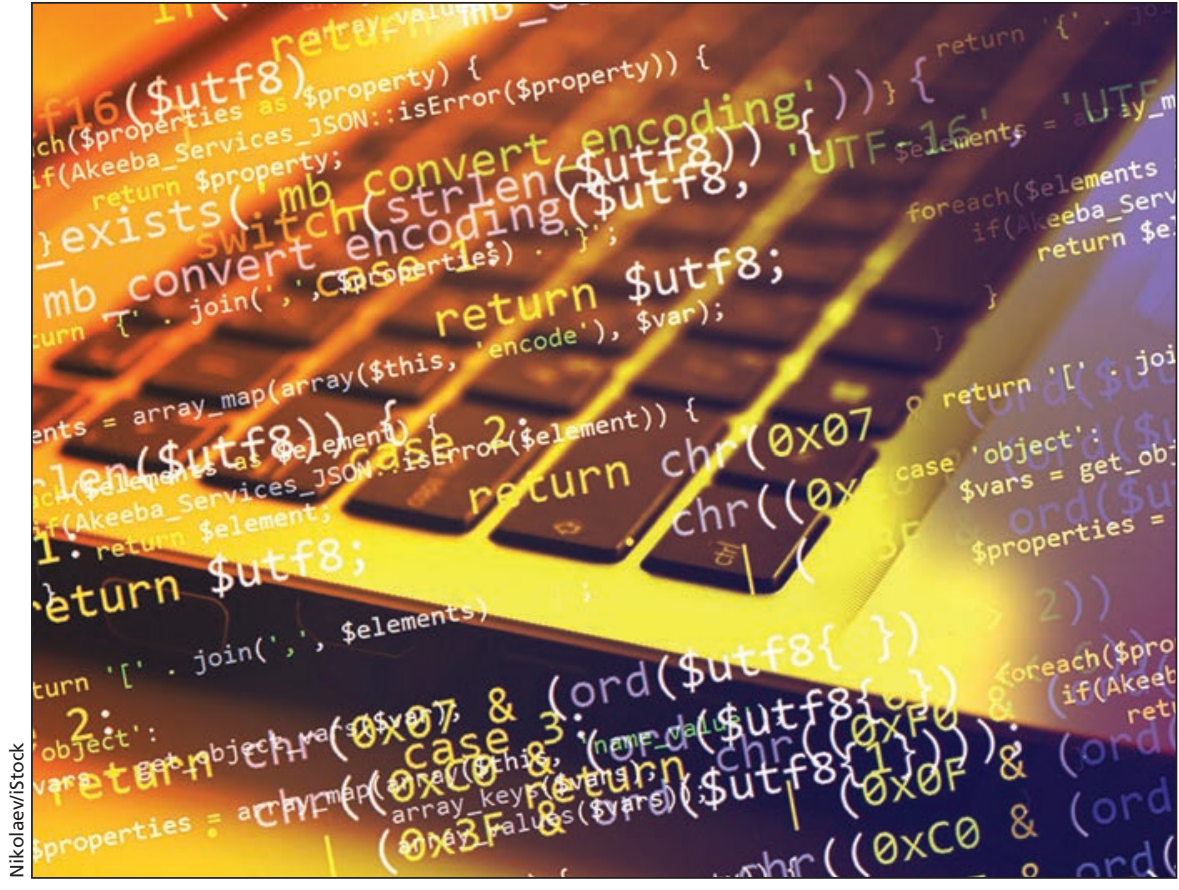

Ironically, Canada is a data-rich nation with poor access to that information. Ironic, but tragic too, because that data could improve health care in Canada.

The data will stay within the originating province, thus mitigating legislative and privacy barriers. Existing pan-Canadian networks that are more limited in scope, such as the Canadian Chronic Disease Surveillance System and CNODES, show that this approach can work.

The network potentially gives researchers the opportunity to assess and learn from the natural policy experiments inherent in Canada's system of provincially delivered health care. "We have some consistency in our framework but different implementation, which creates an opportunity to learn from each other that we haven't taken advantage of to the degree that we could," McGrail said.

The consortium so far includes 140 researchers, policy-makers and health care providers representing every province. "We're very committed to responding to the needs of the research community," said McGrail. "It's not us building this for us; this is us building for the broader research community." She encourages people to register at www.prhdn.ca for updates.

First up, is an infrastructure for primary care data. The consortium expects to hear about its application for funding from the Canadian Foundation for Inno- vation Cyberinfrastructure Challenge 1 Competition by March 2016. If funding is received, the prototype infrastructure could be established within months.

"That's where everything starts in the health care system," said Robyn Tamblyn, scientific director at CIHR's Institute of Health Services and Policy Research. "From there we can easily go to cancer or irritable bowel disease, or other research areas. There is so much we can learn through this network."

"This is an idea whose time has come," added Alison Paprica, director of strategic partnerships at ICES. Not every jurisdiction will be ready to do everything all at once, she added. "Some provinces, some sectors may make some advances, but they are no longer in isolation so others can learn and build on what others do." - Barbara Sibbald, CMAJ

CMAJ 2015. DOI:10.1503/cmaj.109-5090

\section{More News online}

To read more CMAJ news articles, visit cmaj.ca/site/home/news.xhtml 